\title{
Pelatihan Penggunaan Sosial Media untuk Mengembangkan Akses Pasar bagi UMKM Kabupaten Serang
}

\author{
Sindy Yulia Putri ${ }^{1}$, Wiwiek Rukmi Dwi Astuti ${ }^{2}$, Nurmasari Situmeang ${ }^{3}$ \\ 1,2,3, Universitas Pembangunan Nasional Veteran Jakarta \\ Email: sindyyulia@upnvi.ac.id, wiwiek.rukmi@upnvi.ac.id, \\ nurmasarisitumeang@upnvi.ac.id
}

\begin{abstract}
Abstrack
Dengan kemajuan teknologi digital, UMKM memperoleh peluang yang besar untuk berkiprah di dalamnya. Berbagai UMKM Kabupaten Serang masih mengalami kendala dalam mempromosikan produk-produk dagangan mereka. Program pengabdian kepada masyarakat (PKM) ini bertujuan untuk melakukan transfer pengetahuan mengenai penggunaan sosial media untuk mengembangkan akses pasar bagi UMKM di Kabupaten Serang. Tahun 2020 Indonesia masih menghadapi pandemi covid-19. Oleh karena itu, metode sosialisasi dan pelatihan dilakukan melalui media webinar daring. Metode lainnya yang dilakukan adalah diskusi interaktif. Diskusi ini berguna untuk menemukan solusi dari masalah yang dihadapi pelaku usaha UMKM dalam mengoperasionalisasikan media sosial untuk meningkatkan pendapatan. Hasil dari PKM ini adalah para peserta memahami materi webinar dengan baik yang ditunjukkan dari hasil kuesioner. Sebanyak $72.7 \%$ peserta telah dan akan membuat toko virtual untuk mempromosikan produk mereka dan $63.6 \%$ peserta sangat menyetujui bahwa kemampuan memanfaatkan media sosial wajib dimiliki untuk meningkatkan akses pasar produk UMKM.
\end{abstract}

Kata Kunci: Pelatihan, Sosial Media, UMKM, Serang

\begin{abstract}
With advances in digital technology, MSMEs have great opportunities to take part in it. Various SMEs in Serang Regency are still experiencing problems in promoting their merchandise. This community service program (PKM) aims to transfer knowledge about the use of social media to develop market access for MSMEs in Serang Regency. Indonesia is still facing the Covid-19 pandemic. Therefore, the socialization and training methods are carried out through online webinars with interactive discussion. This discussion is useful for finding solutions to problems faced by MSME business actors in operating social media to increase income. The result of this PKM is that the participants understand the webinar material well. As many as $72.7 \%$ of participants have and will create virtual shops to promote their products and $63.6 \%$ of participants strongly agree that the ability to use social media is a must have to increase market access for MSME products.
\end{abstract}

Keywords: Training, Social Media, UMKM, Serang 
Jurnal ComunitÃ Servizio

Volume 2, Nomor 2, Tahun 2020 Hal 437 - 446

\section{PENDAHULUAN}

Partisipasi Usaha Mikro, Kecil, dan Menengah (UMKM) dalam menyokong perekonomian negara telah terbukti di sejumlah negara berkembang di Asia, seperti India, Laos, Taiwan, termasuk Indonesia. Peran dan posisi UMKM bagi Indonesia termasuk penting karena menjadi salah satu saluran untuk mewujudkan pertumbuhan ekonomi inklusif. Pertumbuhan ekonomi inklusif merupakan pertumbuhan ekonomi yang merata bagi seluruh masyarakat, yang bersifat berkelanjutan dan menjamin pendapatan mayoritas masyarakat. Pertumbuhan yang inklusif memungkinkan semua lapisan masyarakat untuk berpartisipasi dan diuntungkan dari pertumbuhan dan pembangunan ekonomi atas dasar kesetaraan, terlepas dari perbedaan latar belakang sosial ekonomi (Hill, Khan, Zhuang 2012: 2 dalam Negara, 2013).

Sejumlah topik yang menjadi hirauan pemerintah untuk pengembangan UMKM adalah terkait pasar dan bahan baku; SDM dan manajerial; finansial; institusi; dan akses teknologi dan inovasi. Pemerintah Indonesia telah mendorong pembangunan UMKM melalui berbagai program dan kebijakan, seperti melalui sejumlah Kementerian/Lembaga, mengalokasikan APBN yang cukup besar, dan menerbitkan berbagai paket ekonomi. Melalui Kementerian Koperasi dan UKM (KKUKM) telah memfokuskan penajaman indikator dan target kinerjanya yaitu memfasilitasi promosi dan pemasaran produk UMKM sejak tahun 2015 (Renstrabis KKUKM, 2015). Sudaryanto (2013)

$$
\text { e - ISSN : } 2656-677 X
$$

memaparkan yang menghambat perkembangan UMKM Indonesia adalah keterbatasan infrastruktur dan akses pemerintah terkait perizinan dan birokrasi; adanya liberalisasi perdagangan; dan kurangnya akses informasi, khususnya informasi pasar.

Dalam perkembangannya, di siaran pers oleh KKUKM, disampaikan bahwa pada akhir tahun 2019, Indonesia termasuk salah satu negara dengan pertumbuhan $e$ commerce dan startup tercepat di dunia. Kondisi tersebut juga diikuti dengan besarnya jumlah konsumer di pasar digital dan tingginya pengguna media sosial di Indonesia. Oleh karena itu, perlu disadari oleh UMKM bahwa market space bagi produk mereka terbuka lebar. Sehingga yang diperlukan oleh UMKM adalah program pembinaan yang mampu mengarahkan mereka kepada peningkatan daya saing dalam mengoptimalkan digital market space tersebut. 


\section{Gambar 1.1 Total Pengguna Internet di Dunia Tahun 2019 (dalam juta)}

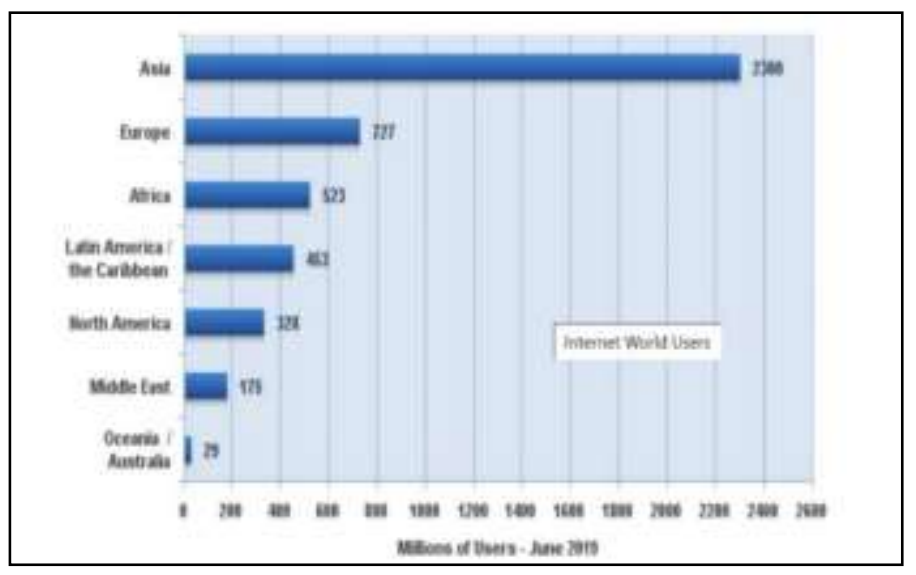

Sumber: Internet World Stats, diakses dari https://www.internetworldstats.com/stats.htm (05/02/2020, 10:35 WIB)

Gambar 1.1 menunjukkan, bahwa kawasan Asia menempati posisi tertinggi untuk jumlah pengguna internet. Dari sumber data yang sama, dinyatakan bahwa $63,5 \%$ dari total penduduk Indonesia merupakan pengguna aktif internet, dimana 48,2\% juga merupakan pengguna media social Facebook. Fakta bahwa Indonesia telah menyepakati berbagai kesepakatan dagang baik secara bilateral maupun multilateral, menjadi faktor pendukung bagi pengembangan UMKM di Indonesia. Dengan memanfaatkan besarnya pengguna internet baik di tingkat nasional, maupun Asia, yang mayoritas juga menjadi pengguna kerangka e-commerce, maka penguasaan pasar menjadi prasyarat untuk meningkatkan daya saing UMKM.

Priambada (2015) dalam tulisannya yang berjudul Manfaat Penggunaan Media Sosial pada UKM menyatakan bahwa media sosial yang paling umum dan banyak digunakan adalah facebook, website, dan e-mail. Dikemukakan bahwa media sosial dimanfaatkan oleh mayoritas UKM untuk mengadakan kontak personal dengan konsumen, promosi atau advertising, mendata kebutuhan konsumen dan menyampaikan respon ke konsumen. Selanjutnya gambar 1.2 menggambarkan, bahwa media sosial menjadi media komunikasi yang efektif bagi UKM khususnya dalam hal mempermudah komunikasi efektif antara pengelola UKM, konsumen dan pemasok, meningkatkan pemasaran dan memperluas pangsa pasar, membantu meningkatkan pengetahuan pengelola UKM dan membantu keputusan bisnis. Jadi, konsistensi dan kepraktisan penggunaan media sosial dapat meningkatkan volume penjualan yang signifikan (Priambada, 2015), seperti pembaharuan secara berkala dan unggah informasi atau produk yang konsisten. 
Gambar 1.2 Manfaat Penggunaan Media Sosial

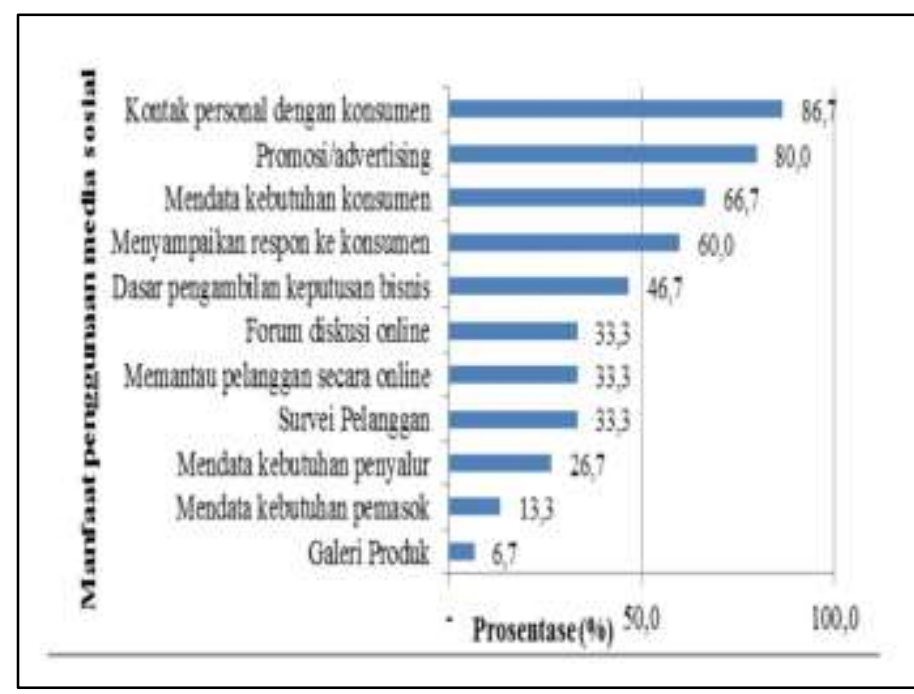

Sumber: Swasta Priambada. 2015. Manfaat Penggunaan Media Sosial pada Usaha Kecil Menengah (UKM). Seminar Nasional Sistem Informasi Indonesia, 2-3 November 2015, hal 44

Selaras dengan hal di atas, Isnanda, dkk (2018) menemukan bahwa teknologi informasi memiliki peranan penting dalam memasarkan produk UMKM di Subang. Namun, pelaku UMKM di Kabupaten Subang belum mengoptimalkan pemasaran melalui jejaring media sosial. UMKM di Subang memanfaatkan teknologi informasi sebatas penggunaan situs untuk pemasaran. Ditemukan bahwa para pelaku UMKM di Subang belum memiliki kemampuan digital yang mumpuni, yang mana pemasaran melalui media sosial masih dilakukan secara acak dan dalam skala kecil. Kondisi ini mengakibatkan tidak adanya dampak yang signifikan terhadap pemasaran produk.
Berdasarkan paparan di atas, rencana pengabdian kepada masyarakat ini, secara spesifik berangkat dari hasil kegiatan pengabdian masyarakat I Nyoman Aji Suadhana Rai dkk (2019) mengenai pemberdayaan UKM melalui kemitraan dengan Pemerintah Kabupaten (Pemkab) Serang dalam kegiatan sosialisasi $e-$ commerce diperoleh bahwa para pelaku UMKM (SDM/tenaga kerja) masih belum memahami sepenuhnya bagaimana memanfaatkan teknologi untuk mempromosikan produk dan meningkatkan penetrasi pasar. Melalui program pemberdayaan tersebut, disinyalir adanya peningkatan minat dan pemahaman pelaku usaha UKM dalam mengoperasionalisasi gawai untuk meningkatkan intensitas promosi produk UKM agar lebih dikenal di masyarakat, khususnya melalui akses dunia maya. Oleh karena itu, dengan target peserta yang sama, urgensi pelatihan penggunaan media sosial bagi pelaku UKM di Kabupaten Serang bersifat signifikan. Pentingnya peranan institusi dan tata kelola merupakan pesan sentral dari pertumbuhan ekonomi inklusif, yang dalam konteks ini akan diperankan oleh UPN Veteran Jakarta dan Diskoperindag Kabupaten Serang.

\section{Permasalahan Mitra}

Dinas Koperasi Perindustrian dan Perdagangan (Diskoperindag) Kabupaten Serang telah menetapkan target UMKM pemula untuk dapat memasarkan produk 
mereka secara daring. Kepala Bidang (Kabid) UMKM Diskoperindag Kabupaten Serang, Vita Agustini memaparkan bahwa sejak tahun 2018, Diskoperindag setiap tahun menargetkan 145 UMKM untuk dapat dapat menjual produknya melalui online. Lebih utamanya, yaitu bagi UMKM yang baru memulai usaha atau pemula. Diskoperindag telah memiliki laman daring yang bernama Gerai Due Kite yang memfasilitasi promosi produk-produk UKM Serang. Namun Diskoperindag memaparkan bahwa optimalisasi pemanfaatan Gerai Due Kite masih belum maksimal dan Pemkab Serang masih membutuhkan upaya yang bersifat resiprokal dari pihak internal dan masyarakat pelaku usaha UKM sendiri (Rai, 2019:192).

Kategori UMKM yang difokuskan untuk memperoleh pembinaan penggunaan akses internet mayoritas di bidang pengolahan, misalnya pengolahan singkong menjadi keripik. Sementara, untuk UMKM bidang peternakan atau pertanian proses pemasarannya rata-rata bersifat manual atau menjual langsung ke konsumennya (KabarBanten, 2020). Pembiasaan penggunaan internet sebetulnya telah digagas secara matang oleh Diskoperindag. Hal ini dapat dijelaskan bahwa saat ini pelaku UMKM telah dipermudah dalam mengurus izin usaha mereka. Pelaku UMKM tidak perlu melakukan pengurusan perizinan secara manual, karena sudah dapat dilakukan melalui daring. Pengurusan perizinan tersebut menggunakan online single submission (OSS) dan Diskoperindag mengakui bahwa prosesnya tidak memakan waktu banyak, bahkan hanya dalam beberapa menit sudah langsung mendapatkan surat izin usaha.

Selanjutnya, Pemkab Serang juga terus mendorong penetrasi pasar produk UMKM pada era industri digital ini. Misalnya pada Oktober 2020, Pemkab Serang menyepakati Memorandum of Understanding (MoU) dengan dua marketplace terkemuka di Indonesia, yakni Bukalapak.com dan Belanja.com. Dilansir dari detiknews, Bupati Serang Ratu Tatu Chasanah menjelaskan kerja sama dengan marketplace adalah program utama dalam pemberdayaan dan pengembangan UMKM. la meyakini dengan penjualan sistem online (e-commerce), kemajuan ekonomi rakyat akan semakin pesat (Medianti, 2019).

Mengacu pada kondisi di atas, maka program pengabdian kepada masyarakat ini akan berusaha melakukan transfer of knowledge mengenai penggunaan sosial media untuk mengembangkan akses pasar bagi UMKM di Kabupaten Serang. Program ini juga akan bekerja sama dengan Pemkab Serang. Kemitraan ini nantinya akan menghasilkan kegiatan pembelajaran yang kontributif mengenai pemanfaatan social media untuk meningkatkan pemasaran produk UMKM Kabupaten Serang.

\section{METODE}

Dikarenakan pandemi covid-19, program pengabdian kepada masyarakat (PKM) ini diselenggarakan dengan metode sosialisasi dan pelatihan dengan media 
webinar secara daring. Metode berikutnya adalah diskusi interaktif dengan para peserta webinar. Pendekatan ini berguna untuk meningkatkan interaksi narasumber dengan para peserta webinar dan membuat webinar menjadi lebih menarik.

\section{HASIL DAN PEMBAHASAN}

Kegiatan PKM diselenggarakan melalui webinar daring dengan judul "Pelatihan Penggunaan Sosial Media untuk Mengembangkan Akses Pasar bagi UMKM Kabupaten Serang". Webinar ini dilaksanakan pada hari Kamis, 10 September 2020, pukul 09.00-11.00 WIB dengan menggunakan google meet. Webinar diikuti oleh 78 peserta yang terdiri dari pelaku usaha UMKM dan UKM Kabupaten Serang, serta mahasiswamahasiswa UPN Veteran Jakarta. Sebagian besar mahasiswa yang mengikuti pelatihan ingin belajar mengenai teknologi digital untuk kewirausahaan dan ada juga dari mereka yang telah memiliki usaha yang didagangkan secara virtual. Para peserta dengan mudah masuk ke dalam ruang virtual google meet. Mereka mengisi daftar hadir sebelum webinar dimulai dan 10 menit sebelum webinar berakhir, mereka mengisi kuesioner. Mitra PKM ini adalah Dinas Koperasi, Perindustrian, dan Perdagangan yang diwakili oleh Kepala Bidang Usaha Mikro yaitu Dra. Vita Agustina, MM. Moderator di webinar adalah Dra. Nurmasari Situmeang, M.Si. Sementara Sindy Yulia Putri, S.Pd., M.Si berperan sebagai narasumber pertama dan mempresentasikan materi mengenai "E-Commerce sebagai Media Promosi untuk Produk UMKM". Sementara Wiwiek Rukmi Dwi Astuti, S.IP., M.Si berperan sebagai narasumber kedua dengan judul presentasi "Kiat Sukses Dagangan Laris di Instagram".

Selama webinar daring berlangsung, para peserta sangat antusias dan aktif dalam memberikan pertanyaan dan menanggapi presentasi narasumber. Setelah presentasi materi dari kedua narasumber selesai, para peserta menanyakan berbagai hal di sesi tanya jawab (Q n A), seperti:

1) Adakah waktu tertentu yang cocok untuk pemasaran produk UMKM lewat e-commerce?

2) Apabila jika followers instagram kita banyak dapat membuat pembeli tertarik untuk membeli produk yg kita jual? Begitu juga sebaliknya jika followers instagram kita sedikit, apakah akan sedikit juga peminatnya?

3) Bolehkah saya meminta tips bagaimana menjaga mood agar selalu konsisten posting produk?

4) Bagaimana cara memperbanyak follower? Apakah foto profil sangat berpengaruh dalam meningkatkan penjualan?

5) Bagaimana caranya kita mencegah perang harga, jika produk kita sama dengan kompetitor? 
6) Yang manakah lebih efektif, apakah facebook atau instagram untuk menarik pelanggan di media sosial?

7) Bagaimana solusinya jika kita menghadapi modus dan banyak konsumen yang meminta cash on delivery (COD)?

8) Apa sajakah syarat suatu produk untuk dijual di toko virtual Shopee?

9) Kapan sebaiknya kita melalukan posting iklan? Apakah setiap hari atau berjeda per dua hari agar konsumen tidak bosan?

10) Bagaimana cara meningkatkan penjualan di toko virtual ketika masa pandemi?

Sembari mengajukan pertanyaan, para peserta juga mengisi kuesioner tertutup berbentuk skala likert yang berisi nama, nomor handphone, jenis usaha, merek produk, akun instagram bisnis, dan tujuh peryataan dalam skala likert, yaitu

1) Saya telah memahami pentingnya media sosial dalam menjalankan usaha

2) Saya percaya bahwa pemanfaatan media sosial akan meningkatkan omzet saya

3) Saya tertarik untuk memanfaatkan media sosial dalam meningkatkan akses pasar produk saya

4) Saya mampu memanfaatkan akses dan informasi di internet untuk menggunakan media sosial untuk bisnis

5) Saya setuju bahwa pelaksanaan produksi produk sama pentingnya dengan penguasaan akses pasar

6) Saya setuju materi pelatihan Penggunaan Sosial Media untuk Mengembangkan
Akses Pasar bagi UMKM yang diberikan bermanfaat

7) Saya telah/akan mendaftarkan usaha saya di media sosial

Berikut hasil kuesioner dari berbagai pernyataan di atas:

\section{Grafik 2.1 Minat UMKM Memanfaatkan Media Sosial untuk Meningkatkan Akses Pasar produk}

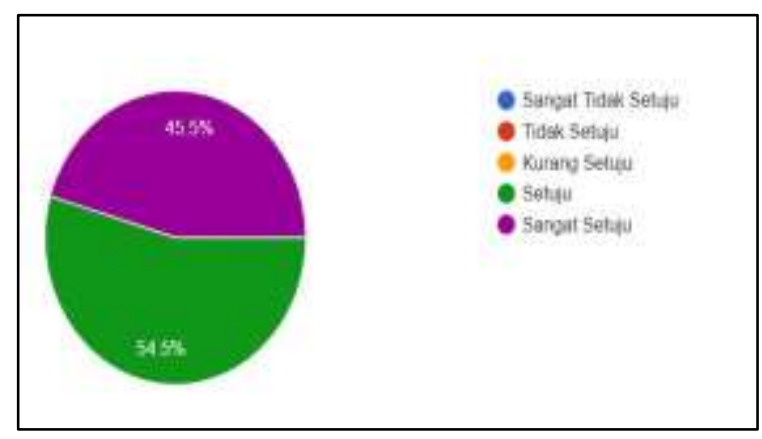

Grafik 2.1 di atas mendeskripsikan lebih dari setengah peserta $(54.5 \%)$ setuju, bahwa pelaku usaha UMKM dan UKM sebenarnya tertarik untuk memanfaatkan media sosial demi meningkatkan akses pasar produk mereka. Namun selama ini, mereka masih kurang mahir dalam menggunakan teknologi digital. Kemudian pelaku usaha UMKM dan UKM juga sebagian besar (72.7\%) menyetujui, bahwa produksi produk dan penguasaan akses pasar adalah dua hal yang sangat penting dan saling berkaitan satu sama lain. Hal ini direpresentasikan dari grafik 2.2 di bawah ini. 
Grafik 2.2 Pentingnya Produksi Produk dan Penguasaan Akses Pasar

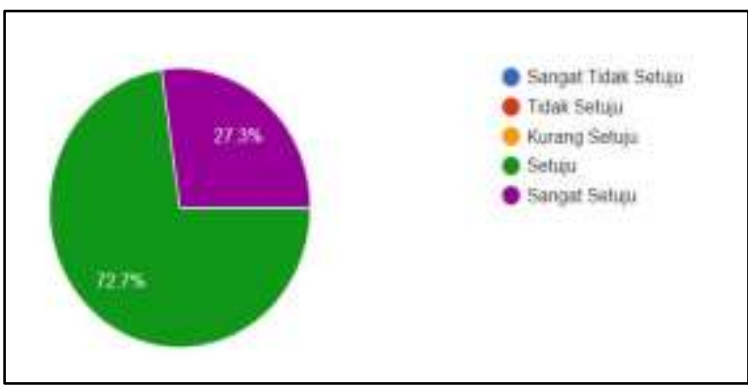

Grafik 2.3 Kemampuan Memanfaatkan Media Sosial untuk Bisnis

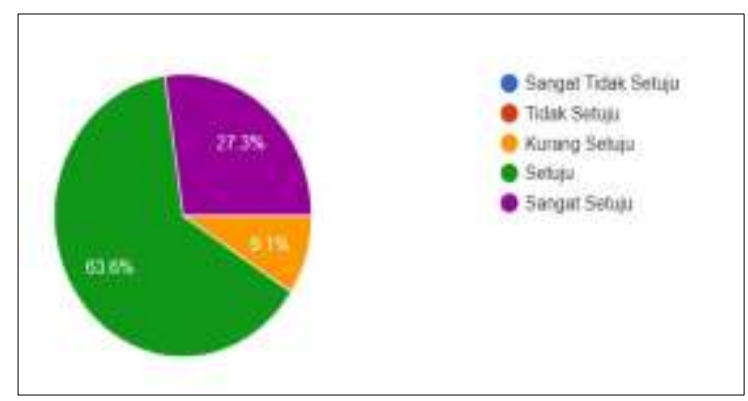

Kemudian grafik 2.3 di atas menjelaskan, bahwa sebanyak $63.6 \%$ pelaku usaha UMKM dan UKM sangat menyetujui bahwa kemampuan memanfaatkan media sosial untuk berbisnis merupakan sesuatu yang wajib dipahami dan dimiliki di masa revolusi industri 4.0 saat ini. Tidak memandang usia, seluruh lapisan masyarakat yang memiliki gawai sebaiknya memahami penggunaan media sosial untuk berjualan secara virtual.
Grafik 2.4 UMKM yang Telah atau Akan Mendaftarkan Usahanya di Media Sosial

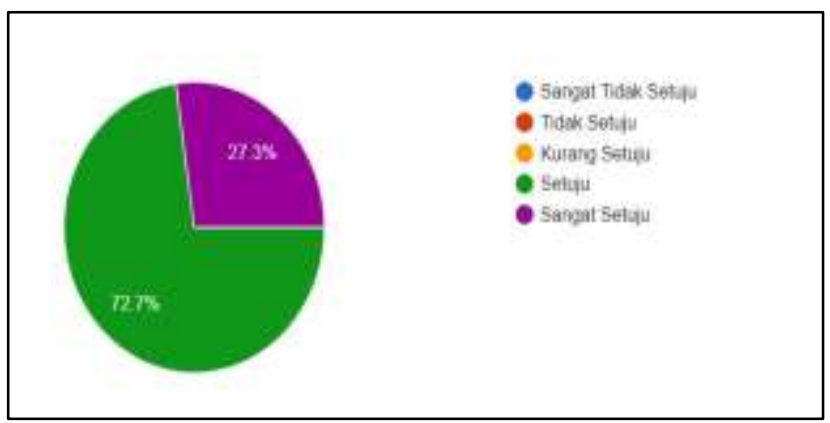

Yang terakhir, grafik 2.4 menunjukkan, bahwa $72.7 \%$ pelaku usaha UMKM dan UKM telah dan akan mendaftarkan usahanya di media sosial. Ada dari mereka yang telah membuka toko virtual atau online shop di beberapa laman e-commerce, seperti Tokopedia dan Shopee. Ada juga dari mereka yang berencana membuka toko virtual di laman virtual e-commerce, namun mereka masih ingin meningkatkan kualitas produk mereka terlebih dahulu sebelum dipasarkan secara daring. Setelah webinar berlangsung selama dua jam, moderator menyimpulkan hasil webinar dan mengakhiri webinar dengan mengucapkan salam. Kemudian para peserta meninggalkan ruang virtual google meet. Webinar juga direkam dan diunggah ke youtube agar dapat disaksikan bersama. 


\section{SIMPULAN}

Rangkaian kegiatan PkM mencakup pengajuan proposal, pelaksanaan webinar daring, penulisan laporan kemajuan, dan laporan akhir. Program PkM dengan judul "Pelatihan Penggunaan Sosial Media untuk Mengembangkan Akses Pasar bagi UMKM Kabupaten Serang" adalah salah satu wujud dharma pengabdian tim dosen Hubungan Internasional, FISIP, Universitas Pembangunan Nasional Veteran Jakarta dalam berkontribusi untuk meningkatkan pengetahuan masyarakat khususnya pelaku usaha UMKM dan UKM. Program ini telah berkontribusi dalam membantu pelaku usaha UMKM dan UKM untuk menggunakan teknologi digital media sosial sebagai ajang promosi berbagai produk unggulan mereka. Peserta sebagai pelaku usaha UMKM dan UKM dan juga mahasiswa yang memiliki toko virtual di laman e-commerce telah memahami penggunaan dan operasionalisasi media sosial seperti instagram dan laman e-commerce. Mereka juga telah memahami bagaimana cara membuka toko virtual di Shopee, mengisi deskripsi produk, membuat diksi yang menarik, dan membuat akun virtual untuk pembayaran daring. Pembuatan toko virtual ini tentunya untuk meningkatkan intensitas promosi produk UKM mereka agar lebih dikenal di masyarakat dunia nyata maupun dunia maya. Tentu program PkM ini masih belum sempurna. Di kemudian hari, tim PkM akan lebih berupaya dalam mengembangkan ilmu pengetahuan dan mengemasnya dengan lebih baik agar lebih terasa manfaatnya bagi masyarakat.

\section{UCAPAN TERIMA KASIH}

Penulis mengucapkan terima kasih kepada tim PKM, LPPM UPN Veteran Jakarta, para peserta yang terdiri dari pelaku usaha UMKM dan UKM Kabupaten Serang, dan Diskoperindag Serang Banten.

\section{REFERENSI}

Detiknews. 22 Oktober 2019. Pasarkan Produk UMKM, Pemkab Serang Gandeng Bukalapak. https://news.detik.com/berita/d4756229/pasarkan-produk-umkm-pemkabserang-gandeng-bukalapak $\quad$ (05/02/2020, 15:00 WIB)

Munajat, E. (2018). Analisis Penggunaan Media Sosial untuk Mendukung Pemasaran Produk UMKM (Studi Kasus Kabupaten Subang, Jawa Barat). Jurnal Pengabdian Kepada Masyarakat, 2(10), 896-899.

Negara, S. D. (2013). Membangun perekonomian Indonesia yang inklusif dan berkelanjutan. Masyarakat Indonesia, 39(1), 247-262.

Rai, I. N. A. S., Putri, S. Y., \& Astuti, W. R. D. (2019). IPTEKS BAGI MASYARAKAT: PEMBERDAYAAN UKM MELALUI KEMITRAAN DENGAN PEMERINTAH KABUPATEN SERANG DALAM KEGIATAN SOSIALISASI ECOMMERCE. JURNAL ComunitÃ 
Volume 2, Nomor 2, Tahun 2020 Hal 437 - 446

$\begin{array}{lrr}\text { Servizio: Jurnal Terkait } & \text { Kegiatan } \\ \text { Pengabdian kepada } & \text { Masyarakat, } \\ \text { terkhusus } & \text { bidang } & \text { Teknologi, } \\ \text { Kewirausahaan } & \text { dan } & \text { Sosial }\end{array}$

Kemasyarakatan, 1(2), 186-197.

Sudaryanto, R., \& Wijayanti, R. R. (2013).

Strategi pemberdayaan UMKM

menghadapi pasar bebas Asean. Pusat

Kebijakan Ekonomi Makro. Badan

Kebijakan Fiskal. Kementerian Keuangan, Jakarta.

Kabar Banten. 1 Februari 2020. 145 UMKM di Kabupaten Serang Ditarget Masuk Pasar

Daring. https://www.kabar-banten.com/145umkm-di-kabupaten-serang-ditarget-masukpasar-daring/ (05/02/2020, 11.25 WIB).

Priambada, Swasta. 2015. Manfaat Penggunaan Media Sosial pada Usaha Kecil Menengah (UKM). Seminar Nasional Sistem Informasi Indonesia, 2-3 November 2015, 41-46 